e-Mosaicos - Revista Multidisciplinar de Ensino, Pesquisa, Extensão e Cultura do Instituto de Aplicação Fernando Rodrigues da Silveira (CAp-UERJ) ANO 1 - V. 1 - N. 1 - JUNHO 2012 - ISSN: 2316-9303

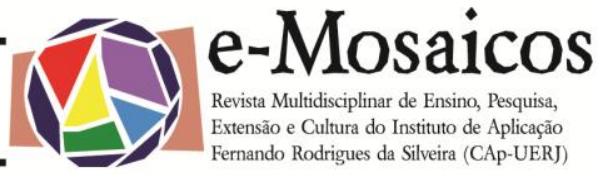

\title{
HISTÓRIA E MEMÓRIA DAS PRÁTICAS ALFABETIZADORAS NO CAp-UERJ
}

\author{
Milena Gomes Coutinho Pereira ${ }^{1}$ \\ Natasha Hermida Pereira Castro da Silva ${ }^{2}$ \\ FFP/UERJ \\ Jacqueline de Fátima dos Santos Morais ${ }^{3}$ \\ FFP/UERJ e CAP-UERJ
}

\section{RESUMO:}

Este trabalho é resultado do Projeto de Pesquisa "História e Memória da Alfabetização no CAp-UERJ e se encontra intimamente articulado a dois Grupos de Pesquisa cujo diálogo tem se estabelecido com bastante fertilidade para nós: "Formação em Diálogo: Narrativas de Professoras, Currículos e Culturas", grupo de pesquisa vinculado ao Instituto de Aplicação Fernando Rodrigues da Silveira (CAp-UERJ) e ao "Núcleo de Pesquisa e Extensão Vozes da Educação: Memória e História das Escolas de São Gonçalo", ligado à Faculdade de Formação de Professores.

A proposta de investigação "Memória e História da Alfabetização no CAp-UERJ" tem como objetivo o resgate da memória da história da instituição, o Instituto de Aplicação da UERJ, a partir do resgate de uma parte de sua história: a das práticas alfabetizadoras. O resgate das memórias e, portanto, das histórias dos sujeitos da escola cria um movimento de reconhecimento desses como principais narradores da própria história. A busca pela rememoração do vivido pelos sujeitos através da narrativa pode permitir a reflexão sobre a sua própria história e sobre a importância e necessidade de registrar e organizar os registros da história vivida e narrada. Nossa ação neste projeto tem por fim a organização de um espaço onde essa história possa ter lugar de existência: um lugar articulado ao Centro de Memória do CAp, já em processo de organização pela professora Leila Medeiros.

PALAVRAS-CHAVE: memória - alfabetização - história

\section{ABSTRACT:}

This work is a result of Project Research "History and Memory of Literacy in CAp-UERJ and is closely articulated to two groups Research whose dialogue has been established with considerable fertility to us: "Training in Dialogue: Narratives of Professors, and Resumes Cultures", the search group linked to the Office of Application Fernando Rodrigues da Silveira (CAp-UERJ) and the" Nucleus Research and Extension Voices of Education: Memory and History of Schools of São Gonçalo, "connected to the Teachers Training College. The proposed research "Memory and History of Literacy in CAp-UERJ" aims to rescue the memory of the history of the institution, the 
e-Mosaicos - Revista Multidisciplinar de Ensino, Pesquisa, Extensão e Cultura do Instituto de Aplicação Fernando Rodrigues da Silveira (CAp-UERJ) ANO 1 - V. 1 - N. 1 - JUNHO 2012 - ISSN: 2316-9303

Institute for Application of UERJ, from the redemption of a portion of its history: the practical literacy. The redemption of memories, and therefore the stories of the subjects of the school, creating a movement for recognition as the main narrators of own history. The search for remembrance lived by the subject through the narrative, may allow reflection on its history and on the importance and need to register and organize the records of history lived and narrates. Our action in this project is to the organization of an area where this history can be made of existence: a place articulated the Centre of Memory CAp, already in the process of organizing the teacher Leila Medeiros.

KEY WORDS: memory - literacy - history

Este trabalho é resultado do Projeto de Pesquisa "História e Memória da Alfabetização no CAp-UERJ", um projeto cadastrado na Universidade do Estado do Rio de Janeiro e que hoje possui 3 bolsistas de Iniciação Científica, sendo duas voluntárias. Nosso projeto se encontra intimamente articulado a dois Grupos de Pesquisa cujo diálogo tem se estabelecido com bastante fertilidade para nós: "Formação em Diálogo: Narrativas de Professoras, Currículos e Culturas", grupo de pesquisa vinculado ao Instituto de Aplicação Fernando Rodrigues da Silveira (CApUERJ) e o "Núcleo de Pesquisa e Extensão Vozes da Educação: Memória e História das Escolas de São Gonçalo", ligado à Faculdade de Formação de Professores. Essa dupla identidade se deve ao fato de estarmos nas duas unidades acadêmicas, buscando desenvolver tanto ações de natureza extensionista quanto de natureza investigativa, além de uma de nós, Jacqueline Morais, ser docente em ambas instituições. Defendemos que não apenas o espaço da graduação, em nosso caso a Faculdade de Formação de Professores de São Gonçalo, seja considerado como o espaço da tradição da pesquisa na universidade, mas também no espaço do Ensino Fundamental, tal como o é o CApUERJ, seja reconhecido como legítimo produtor de conhecimento. Foi a partir da defesa de que toda professora tem o direito de assumir a tríade que compõe sua identidade docente - tríade que se funda pela docência, extensão e pesquisa - mesmo estando nos anos iniciais do ensino fundamental, lugar tradicionalmente visto como lugar da ação cotidiana, menos que a da reflexão cotidiana, que foi fundado no Departamento de Ensino Fundamental do Instituto de Aplicação Fernando Rodrigues da Silveira (CApUERJ), no ano de 2006, o primeiro grupo de pesquisa. O GPFORMADI nasce, portanto, de uma inquietação e de um desejo de assunção legítima.

Não é sem razão que neste projeto de investigação tomamos o CAp, sua história, suas práticas pedagógicas, seu cotidiano, como lócus de pesquisa, e propomos implicações desta pesquisa para a Faculdade de Formação de Professores. Estreitar os laços entre as diferentes unidades acadêmicas, por meu turno entre a FFP e o CAp-UERJ, através de ações e investigações que provoquem e alimentem a parceria entre as unidades, criando um novo lugar para ambos não mais hierarquizado, horizontalizado, mas tecido pelo diálogo permanente que possibilita o reconhecimento das singularidades de cada uma das unidades - é um sentido que me move a propor esta pesquisa pensando caminhos colaborativos.

Assim, a proposta de investigação 
e-Mosaicos - Revista Multidisciplinar de Ensino, Pesquisa, Extensão e Cultura do Instituto de Aplicação Fernando Rodrigues da Silveira (CAp-UERJ) ANO 1 - V. 1 - N. 1 - JUNHO 2012 - ISSN: 2316-9303

"Memória e História da Alfabetização no CAp-UERJ"está articulada à docência, extensão e pesquisa nas duas unidades, com vínculos nos dois grupos de pesquisa aos quais hoje nos ligamos. Tem como objetivo o resgate da memória da história da instituição, o Instituto de Aplicação da UERJ, a partir do resgate de uma parte de sua história: a das práticas alfabetizadoras. $\mathrm{O}$ resgate das memórias e, portanto, das histórias dos sujeitos da escola cria um movimento de reconhecimento destes como principais narradores da própria história. A busca pela rememoração do vivido pelos sujeitos através da narrativa pode permitir a reflexão sobre a sua própria história e sobre a importância e a necessidade de registrar e organizar os registros da história vivida e narrada. Nossa ação neste projeto tem por fim a organização de um espaço onde essa história possa ter lugar de existência: um lugar articulado ao Centro de Memória do CAp, já em processo de organização pela professora Leila Medeiros, cuja necessidade já vem sendo sinalizado a tempos pelas professoras do Departamento do Ensino Fundamental e que neste ano tem tomado força com a comemoração dos 50 anos do CAp.

A sistematização dos registros da memória escolar e das práticas dos sujeitos nos parece de fundamental importância, constituindo uma relevante justificativa neste projeto, pois que contribui não só para a história da educação, mas em especial para a dimensão pesquisadora da formação docente, pois como afirma PARK (2003:34)

As memórias das professoras povoam suas práticas, às vezes de forma errante, sem grandes reflexões, assumidas após trabalhos de análise solitárias ou de grupo. Trabalhadas como memórias coletivas, irão produzir um texto que possibilitará a compreensão de práticas assumidas no cotidiano.

O desenvolvimento de espaços de memória institucional traz a necessidade de problematizarmos nossa história, sistematizando reflexões, organizando registros, materiais diversos, com intuito de dar certa organicidade à memória e, portanto, à história, sem esquecer também que os dados gerados durante a investigação precisam ser de acesso a todos os interessados, ficando disponível em lugar adequado. Assim organizado em Centro de Memória, o acesso de outros sujeitos à história das práticas alfabetizadoras do CAp-UERJ - pesquisadores, professores, alunos, familiares - pode representar um avanço na construção e socialização de um material que não se perpetua como privado mas que amplia seus usos e funções para outros sujeitos.

Em um tempo em que o pouco valor das experiências vividas, a rapidez, o imediatismo e a alienação parecem imperar, querer partilhar histórias, experiências, acontecimentos, parecem significar agir a contrapelo: buscar um outro tempo e um outro lugar. Um tempo que permite a lentidão das palavras, da respiração entre as frases ditas, tempo que possibilita durante os diálogos 0 fiar ou o tecer (Benjamin, 1985: 205), tempo de compartilhar - de partilhar com 0 outro.

Perez (2003) nos adverte que:

Num tempo veloz e fugaz, em que a alienação, $\mathrm{o}$ isolamento $\mathrm{e}$ o silenciamento das experiências, nos forçam a perder nossa memória coletiva, rememorar e 
e-Mosaicos - Revista Multidisciplinar de Ensino, Pesquisa, Extensão e Cultura do Instituto de Aplicação Fernando Rodrigues da Silveira (CAp-UERJ) ANO 1 - V. 1 - N. 1 - JUNHO 2012 - ISSN: 2316-9303

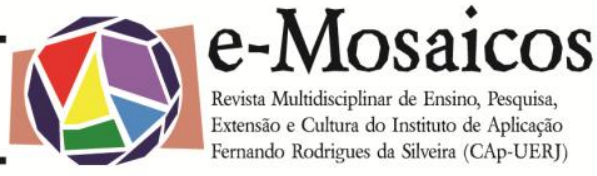

compartilhar memórias é uma ação rebelde que adquire um caráter de resistência política _ a memória compartilhada é uma forma de não sucumbir ao esquecimento que o tempo acelerado da vida social nos impõe.

Quando compartilhamos memórias e experiências que são pessoais porque vividas por nós, mas que são, ao mesmo tempo, coletivas, além de mobilizarmos conteúdos que são individuais, acordamos sentidos construídos na vida coletiva, sentidos que são nossos, mas são, ao mesmo tempo, de nosso tempo e lugar. Sentidos rebeldes, sentidos moventes, sentidos de vida e do trabalho.

A ação rebelde de que fala Perez, ação que implica não deixar morrer o que se viveu, é, portanto, individual, mas também, profundamente, coletiva. O passado, ao ser compartilhado, ao trazer as memórias e as experiências de cada um, aqui a história das práticas alfabetizadoras do CAp, vai revelar que esse passado não é posse nem da história, nem de um só sujeito, como chega a afirmar Benjamin (1985:223). A tarefa de não sucumbir ao esquecimento, também não pode ser de apenas um: ela precisa ser comunitária.

Assim, cremos, como Perez (2003) que:

Compartilhar memórias é uma forma de reinventar a comunidade, de construir redes de solidariedade que através do exercício de outras formas de relacionamento, nos possibilitem estabelecer novos modos de sociabilidade democrática e novas formas de criatividade social.
Ressignificando o espaço-tempo das práticas alfabetizadoras no CAp poderemos compreendê-las não apenas como lugar de conhecimento mas como um lócus de autoconhecimento, como nos ensina Boaventura Santos (1995).

A questão que atravessa a proposta desta pesquisa, portanto, leva à busca de caminhos que possibilitem a compreensão dos percursos de constituição das práticas docentes que hoje vivem e sobrevivem no CAp. Benjamin (1985) nos ajuda nesse processo de reflexão, pois para ele a centralidade da narrativa e da linguagem se sobrepõe na medida em que é na linguagem e pela linguagem que podemos romper com 0 homem coisificado. Na medida em que, narrando, não resumimos nossa vida a vivências - algo imediato e momentâneo, em que o "homem de hoje não cultiva o que pode ser abreviado"(p.206). Ao narrar tornamos nossas experiências comunicáveis, rompendo com a instantaneidade e ressignificandoa.

o narrador figura entre os mestres e os sábios. Ele sabe dar conselhos: não para alguns casos, como o provérbio, mas para muitos casos, como o sábio. Pois pode recorrer ao acervo de toda uma vida - uma vida não inclui apenas a própria experiência, mas em grande parte a experiência alheia. $O$ narrador assimila à sua substância mais íntima aquilo que sabe por ouvir dizer (1985:221)

A narrativa desencadeia um processo de rememoração que torna a troca de experiência possível. Não se trata de reviver o passado, sendo que: 
e-Mosaicos - Revista Multidisciplinar de Ensino, Pesquisa, Extensão e Cultura do Instituto de Aplicação Fernando Rodrigues da Silveira (CAp-UERJ) ANO 1 - V. 1 - N. 1 - JUNHO 2012 - ISSN: 2316-9303

articular historicamente o passado não significa conhecê-lo como ele foi de fato. Significa apropriar-se de uma reminiscência tal como ela relampeja no momento do perigo. $(1985: 224)$

O movimento desencadeado pela rememoração das práticas alfabetizadoras do CAp-UERJ se constitui como um momento não só de compreensão do passado mas de redimensionar o passado a partir do presente também ressignificado.

Mas o que poderíamos dizer acerca da memória? Como nos acercar de seus sentidos? Primeiro poderíamos ir em busca de um sentido dicionarizável. Ajudaria-nos a entender essa faculdade humana? No Dicionário Luft (1995: 416) encontramos as seguintes definições, dentre outras: "faculdade de lembrar, reter impressões, idéias. Recordação." O que estas palavras nos dizem sobre memória?

E resgate? Por mesma fonte encontramos: "livrar do cativeiro. Libertação".

Nosso projeto buscaria, então, a "libertação do passado"? Pensar em tal expressão nos dá a sensação de que o passado fora aprisionado, todavia, sob uma lógica benjaminiana esta idéia não procede, visto que o passado não se limita cronologicamente. Assim, discordamos daqueles que afirmam que trabalhar com o passado é resgatá-lo, visto que ele é sempre rememorado e não resgatado. O passado, as experiências vividas no ontem não são libertas da prisão onde se encontram. Elas são relidas, ressignificadas, reacendidas. Não estão presas mas adormecidas, como diz Benjamin. Não libertamos o passado. Acordamos sentidos. Ou tecemos novos.
$\mathrm{Na}$ contramão dos teóricos clássicos, Benjamin não acredita em uma cronologia linear para que haja a transformação, mas sim numa constante viagem de volta em um encontro com as origens para que se façam as mudanças ainda que sob novas bases.

Desse modo, para Benjamin, não se volta ao passado apenas para conhecê-lo, mas para servir-se dele como forma de "colocar o presente numa situação crítica" (Konder, 1988, p.22).

Procuramos por meio da parceria entre UERJ-FFP e CAp-UERJ restituir então esse patrimônio tão valioso que é a memória de tais instituições. Consultando documentos sobre o histórico do CAp-UERJ, descobrimos informações que nos ajudaram a compreender as origens tanto desta instituição quanto do trabalho alfabetizador, foco de nossa investigação atual.

Assim, descobrimos que o Instituto de Aplicação Fernando Rodrigues da Silveira CAp-UERJ, tem sua procedência no Colégio de Aplicação. Suas aulas foram iniciadas no dia $1^{0}$ de abril de 1957 . Nessa época a escola possuía apenas o Curso Ginasial, equivalente, hoje, aos quatro últimos anos do Ensino Fundamental.

O curso era ministrado no turno da manhã, ocupando espaço onde funcionava, em outros horários, os diferentes cursos dos atuais Instituto de Letras, Faculdade de Educação, Instituto de Filosofia e Ciências Humanas e Instituto de Psicologia, então localizados na Rua Haddock Lobo, 296.

Ainda nos anos 60 houve a transferência do colégio para a "colina", como era chamado pelos professores, o Morro do Turano. Pais, professores e o Diretor, professor Fernando Sgarbi Lima, já vinham lutando para buscar um espaço para a escola, separado dos cursos universitários, que ga- 
e-Mosaicos - Revista Multidisciplinar de Ensino, Pesquisa, Extensão e Cultura do Instituto de Aplicação Fernando Rodrigues da Silveira (CAp-UERJ)

ANO 1 - V. 1 - N. 1 - JUNHO 2012 - ISSN: 2316-9303

rantisse maior flexibilidade de horário e autonomia de funcionamento. Houve então a necessidade de adaptação e improviso, pois o prédio na Rua Barão de Itapagipe 311 não atendia às necessidades previstas.

Na década de 70 ampliou-se as relações com a Faculdade de Educação e outros Institutos da Universidade, o que aumentou a procura do CAp-UERJ como campo de estágio e pesquisa para licenciados e diversos outros profissionais.

Foi nessa época que surgiu pela primeira vez a hipótese de se criar o primeiro segmento do $1^{\circ}$ Grau do Colégio de Aplicação. Tal idéia consolidava a perspectiva de que a instituição estava de fato preparada para propor metodologias e servir de campo de estágio para todo o ensino fundamental, e não apenas para seu segundo segmento.

$O$ ingresso dos alunos foi gradativo; a princípio com turmas de $3^{\mathrm{a}}$ e $4^{\mathrm{a}}$ séries $^{1}$, e posteriormente, de $2^{\mathrm{a}}$ e $1^{\mathrm{a}}$ séries. Completado esse ciclo, a entrada no segmento só poderia ocorrer a partir de exame de alfabetização na primeira série, o que viria a ser uma espécie de "vestibulinho"...

O uso das provas chegou ao fim após se consolidar a Classe de Alfabetização. A partir de 1986- até hoje- o ingresso no CapUERJ se realiza por meio de sorteio público, ou por concurso público no que hoje é chamado de $6^{\circ}$ ano de escolaridade (antiga $5^{a}$ série).

Na década de 90, O Instituto de Aplicação mudou novamente seu endereço devido

\footnotetext{
${ }^{1}$ Aqui, em todo o texto a seguir, "série" é a antiga nomeação da organização do tempo escolar que se fazia em um ano nas instituições de ensino. Remete, portanto, a linearidade e progressão de escolaridade. Este tempo, a partir em especial das mudanças conceituais oriundas do currículo organizado por ciclos, passou a ser entendido por anos de escolaridade e não mais por séries.
}

à violência urbana que havia se instaurado no Morro do Turano. Sendo assim, os $3^{\circ} \mathrm{e}$ 40 ciclos do Ensino Fundamental e Médio passaram a residir no Campus Universitário do Maracanã, onde permaneceu de 1994 a 1998.0 primeiro segmento do Ensino Fundamental permaneceu no Pavilhão Nei Cidade Palmeiro, situado na Rua Haddock Lobo.

Como pode-se notar, o Cap-UERJ já residiu em vários endereços, diversas "casas", sedes, prédios... Entretanto, por mais que tais mudanças tenham representado grandes conquistas e tenham se estabelecido de forma a visar sempre o melhor para todos, a memória, ainda que não intencionalmente, saiu perdendo... Esse vai-e-vem do Instituto acabou por deixar, fatalmente, importantes documentos, e conseqüentemente inúmeras explicações, pelo caminho.

Sendo assim, como objetivo primordial de nossa pesquisa, cabe-nos ir à busca dessas lembranças esquecidas pelas calçadas cariocas, pelos armários empoeirados... Cabe-nos rememorar cada memória escondida em livros, objetos, fichas, diários de classe, provas...

A formação da Alfabetização, entretanto, incita-nos uma curiosidade especial...Por que de fato desenvolveu-se? Quais suas origens e objetivos? Sob que contexto pensou-se nela? Com tantas interrogações pairando sobre nós, a pesquisa se deu.

Desejamos reencontrar as peças que restam neste fascinante quebra-cabeça - ou seria jogo da memória?- e assim reconstituir todo o passado histórico que foi de fundamental importância para a formação do presente do CAp, da UERJ, e de toda malha educacional carioca.

Nossa pesquisa consiste, então, em recuperar por fontes documentais e orais qualquer tipo de dado sobre a formação da 
e-Mosaicos - Revista Multidisciplinar de Ensino, Pesquisa, Extensão e Cultura do Instituto de Aplicação Fernando Rodrigues da Silveira (CAp-UERJ) ANO 1 - V. 1 - N. 1 - JUNHO 2012 - ISSN: 2316-9303

classe de alfabetização no CAp-UERJ. Fora proposto trabalhar com esses dois tipos de fonte justamente porque a memória se dá de diferentes formas, formas estas que se complementam.

Sabendo-se que o Instituto de Aplicação Fernando Rodrigues da Silveira (CAp- UERJ) tem uma considerável significância na educação carioca, acreditamos que o acesso a essas informações deva ser geral, por isso, além de pesquisarmos suas origens, ambicionamos também dispor de um local para organização de tais informações. Este local seria um Centro de Memória localizado na própria unidade do CAp. Centro que já se encontra em organização pela dedicação da profa Leila Medeiros.

Desejamos reconstruir os nós que deram origem a essa trama que hoje temos como referência de ensino. Procuramos, com o centro de memória, desenvolver um lugar que incite o movimento, que mobilize a todos. Até porque a memória nos incita movimentos, faz-nos ir ao fundo da alma a procura de ações que nos marcaram de alguma forma. Voltamos, portanto, ao início de nosso texto: o que é a memória?

A arte, por todas as suas vertentes, trata a memória com respeito e em sua maioria com uma ponta de saudosismo. Como na música de Gonzaguinha, a memória parece algo que se foi, mas que deixa um cheiro e um gosto perdido no tempo:

\section{Memória}

\section{Gonzaguinha}

Houve um dia aqui uma praça

Onde tantas crianças cantavam

Houve um dia aqui uma praça

Onde os velhos sorriam lembranças
Houve um dia aqui uma praça

Onde os jovens em bando se amavam

E os homens brincavam trabalhando

Um trabalho sem desesperança

Digo meu filho que esse jardim

Era o viço da vida vingando

Digo meu filho que esse jardim

Era o branco dos dentes brilhando

E a festa da vida seguia

Pelo o franco dos gestos libertos

Digo de fresca memória que não aqui não havia

Do medo este cheiro

Digo de fresca memória que não aqui não havia

De estátuas canteiros

Houve um dia aqui país

uma praça, uma rua, uma esquina, um

houve crianças e jovens e homens e veIhos

um povo feliz.

Tendemos a envergar, como o autor Gonzaguinha, a ver o passado como um tempo que não retorna, como algo que se petrificou, embora constantemente nos esforcemos para dar-lhe ação novamente.

Não temos como garantir que a visão do autor seja a mesma que as pessoas que viveram aquele momento descrito. Talvez, se fossem perguntadas, as pessoas que freqüentavam a tal praça citada teriam uma visão diferenciada de tudo o que as cercava; talvez as crianças citadas nem cantassem 
e-Mosaicos - Revista Multidisciplinar de Ensino, Pesquisa, Extensão e Cultura do Instituto de Aplicação Fernando Rodrigues da Silveira (CAp-UERJ) ANO 1 - V. 1 - N. 1 - JUNHO 2012 - ISSN: 2316-9303

assim, e os jovens ditos não se amassem com a intensidade vista pelo narrador.

Gonzaguinha, porém, afirma tal interpretação a partir de um eixo comparativo com os dias atuais, além de apontar-nos sua preferência pelos tempos de outrora.

Por seu turno, Walter Benjamin (1985) fala-nos sobre a imagem da felicidade que carregamos. Em Sobre o conceito da história dizendo-nos o autor:

... nossa imagem de felicidade é totalmente marcada pela época que nos foi atribuída pelo curso de nossa existência. A felicidade capaz de suscitar nossa inveja está toda, inteira, no ar que respiramos, nos homens com os quais poderíamos ter conversado, nas mulheres que poderíamos ter possuído..

Por isso então, em nossa pesquisa, demos grande importância às fontes orais, visto que ela nos traz relatos carregados de marcas pessoais e, conseqüente, afetuosidade.

Quando as fontes orais surgem de diversas gargantas temos então versões plurais e não a construção verdadeira de um fato. Temos como pressuposto que um depoimento sempre é verdadeiro posto que é real para o sujeito que o produz . Cada fala transforma-se em uma corrente de experiências diversas e únicas.

Benjamin (1985) diz em O Narrador: "O narrador retira da experiência o que ele conta: sua própria experiência ou a relatada pelos outros. E incorpora as coisas narradas à experiência dos seus ouvintes".
Continuando no campo das artes, temos nas artes plásticas, a memória ganhando destaque com o pintor espanhol Salvador Dali em sua famosa obra "A persistência da memória". Vejamos-a:

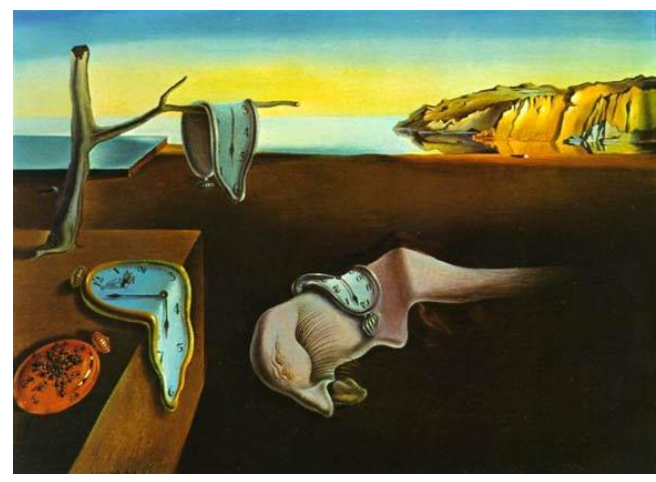

(Salvador Dali- 1931)

Temos, com essa obra, outra visualização da memória. Dalí induz-nos a ver o tempo não como algo petrificado, incitado por Gonzaguinha, mas sim como algo maleável e flexível. Em sua obra surrealista, sempre houve a busca da mescla entre passado e presente, realidade e sonho, que também, como vimos anteriormente, se faz presente ainda que ingenuamente nas narrações.

Sob tal ótica, nossa pesquisa buscou ver a memória também como Dali. Sendo o tempo maleável, a memória também o é. Temos sempre a oportunidade de manuseála dentro de nós, refleti-la de outros ângulos e em outros tempos, e fazer de nossas conclusões um combustível a mais na construção de um novo presente.

No ponto de vista da sétima arte - o cinema - temos o exemplo do filme "Colcha de Retalhos" de direção de Jocelyn Moorhouse, no qual é narrada a história de Finn Dodd (Wynona Ryder), uma jovem mulher que vai morar na casa da sua avó. Lá estão 
e-Mosaicos - Revista Multidisciplinar de Ensino, Pesquisa, Extensão e Cultura do Instituto de Aplicação Fernando Rodrigues da Silveira (CAp-UERJ) ANO 1 - V. 1 - N. 1 - JUNHO 2012 - ISSN: 2316-9303

várias amigas da família, que preparam uma elaborada colcha de retalhos como presente de casamento. Enquanto o trabalho é feito, as senhoras vão rememorando suas vidas e fazendo relatos de paixões e envolvimentos.

Nesse caso, a pesquisa apropriou-se do fato de o filme enfocar a idéia da memória como forma de socializar e criar algo em conjunto.

No filme, o fruto do trabalho é, como o nome enuncia, a colcha de retalhos, e na nossa pesquisa é o centro de memória, onde os retalhos são os relatos e os documentos adquiridos.

No filme, cada retalho é costurado como se desejando que a memória resgatada no instante de tal trabalho pudesse vir a ganhar concretude, afim de que se tornasse palpável.

O retalho em si já é um resquício de memória; uma reminiscência de algo que se foi...todavia, a colcha de retalhos é algo novo! Trata-se de uma mesma matériaprima reciclada pensando-se no presente, ainda que seja inteiramente feita de passado.

O centro de memória tende a ser então um mosaico de reminiscências. Mosaico este que se mobiliza em torno do passado almejando idealizar um novo presente.

Walter Benjamin cita em $O$ Narrador 'Como disse Pascal, ninguém morre tão pobre que não deixe alguma coisa atrás de si. Em todo caso, ele deixa reminiscência, embora nem sempre elas encontrem um herdeiro.".

Refletimos sobre o quanto de informações úteis se apagam da história por não serem transmitidas no popular - e eficaz boca-a-boca. Informações estas que poderiam vir a esclarecer-nos as dúvidas que, em alguns casos, as fontes documentais somente não são capazes.

Utilizando de mesma expressão de Benjamin, o herdeiro seria aquele capaz de se fazer multiplicador dos saberes. O fizemos concreto em nossa pesquisa, não como um narrador propriamente dito, mas como um ambiente onde tudo inspire à reflexões e voltas ao passado.

Um centro de memória em que venha a personificar, de algum modo, as múltiplas vozes de múltiplos ângulos que vieram a influenciar a formação da base atual do CAp-UERJ.

Desejamos não somente dar voz às vozes emudecidas, como também às fotografias, cadernos de registros, listas de presença, e demais contribuições vindouras.

No campo literário, a ocupante da cadeira no82 da academia brasileira de letras, Lygia Fagundes Telles, procura comparar si mesmo em uma espécie de "antes e depois" em seu livro intitulado Invenção e Memória. Nele, a autora narra sob os olhos de uma mulher madura e cosmopolita que é, sua imagem de menina que um dia fora a se desatar em aventuras no interior.

O título de seu livro torna-se curioso porque Lygia assume suas contribuições ficcionais sobre os fatos reais. A autora comenta sobre essa mescla dizendo em entrevista na X Bienal do Livro do Rio de Janeiro: "A memória e a invenção estão misturados. Quando você dá ênfase ao relato de um fato, você sempre acrescenta algo. Logo se torna difícil fazer a distinção, mesmo porque a invenção se torna o sal da memória.".

Por outro lado, quando pensamos em Benjamin (1985) e sua concepção de história, aprendemos que:

Narrar histórias é sempre a arte de as continuar contando e esta 
e-Mosaicos - Revista Multidisciplinar de Ensino, Pesquisa, Extensão e Cultura do Instituto de Aplicação Fernando Rodrigues da Silveira (CAp-UERJ) ANO 1 - V. 1 - N. 1 - JUNHO 2012 - ISSN: 2316-9303

se perde quando as histórias já não são mais retidas. Perde-se porque já não se tece e fia enquanto elas são escutadas. Quanto mais esquecido de si mesmo está quem escuta, tanto mais fundo se grava nele a coisa escutada.

Logo, nossa pesquisa refletiu sobre tal obra de Lygia Fagundes Telles no fato de que a autora admite fazer uso do fictício, todavia, ela demonstra não saber calcular o fino fio que divide a ficção da realidade, e acaba por assumir que um toque de ficção proposital pode vir a engrandecer a obra.

Benjamin confirma em sua citação que de fato quando narramos andamos em uma corda-bamba visto que por mais que continuemos a transmitir as histórias e memórias, não as retemos sob molde original, tendo isso grande impacto posteriormente quando acabamos por assimilar como nato o que nós próprios criamos.

Todavia, não nos cabe pensar em qual dos dois lados (ficção ou realidade) nossos pés pisam, cabe a nós sim, rememorá-la como se encontra marcada em nós.

A formação do Centro de Memória no CAp-UERJ vem a ser não só um espaço com reminiscências próprias e de fundamental importância para o implante da semente da reflexão educacional, como também um convite a todos que desejam instigar a criticidade de suas lembranças pessoais.

\section{REFERÊNCIAS BIBLIOGRÁFICAS:}

BAKHTIN, Mikhail. Marxismo e filosofia da linguagem. São Paulo: Hucitec, 1990.
BENJAMIN, Walter. Obras escolhidas I magia e técnica, arte e política. S. P, Brasiliense, 1985.

Obras escolhidas II - rua de mão única. S. P, Brasiliense, 1987.

GARCIA, Regina Leite (org). A Formação da Professora Alfabetizadora: Reflexões sobre a Prática. São Paulo, Cortez, 1998.

KRAMER, Sonia. Por entre as pedras, arma e sonho na escola. Campinas, Papirus, 1996.

MORAIS, Jacqueline de F. dos Santos. Histórias e narrativas na educação infantil. In: GARCIA, Regina L. (org). Crianças, essas conhecidas tão desconhecidas. Rio de Janeiro: DP\&A, 2002, p.81-101.

- A escola pública e os discursos sobre sua pretensa crise. Teias, Rio de Janeiro. ano 2, n. 4, p. 55-61, 2003.

e ARAÚJO, Mairce da Silva. Alfabetização e analfabetismo no Brasil: algumas reflexões. In: Acolhendo a Alfabetização nos Países de Língua Portuguesa (USP), ano 5, n. 9, p. 105-120, 2010. Disponível em: <http://www.acoalfaplp.net>.

. Que sentidos se escondem sob a suposta face neutra da palavra infância? Poiésis (Catalão), UFG, v. I, p. 46-59, 2003.

MORIN, Edgar. Introdução ao pensamento complexo. Lisboa, Instituto Piaget, 1990.

. Ciência com consciência. Rio de Janeiro, Bertrand Brasil, 1998.

NóVOA, Antônio. Relação escola-sociedade: "novas respostas para um velho problema". In: SERBINO, Raquel Volpato et ali (orgs). Formação de professores. SP, UNESP, 1998.

NÓvOA, Antônio. (org). Vida de professores. Porto, Portugal, 1992. 
e-Mosaicos - Revista Multidisciplinar de Ensino, Pesquisa, Extensão e Cultura do Instituto de Aplicação Fernando Rodrigues da Silveira (CAp-UERJ)

ANO 1 - V. 1 - N. 1 - JUNHO 2012 - ISSN: 2316-9303

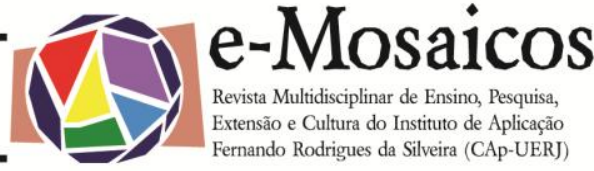

PARK, Margareth B. (org). memória na Formação de professores. Campinas, SP, Mercado das Letras, 2000.

TAVARES, M. T. e ARAÚJO. Implementando núcleo de memória nas escolas: uma experiência na formação de professores. TrabaIho apresentado no Endipe, 2004.

THOMPSON, Paul. A voz do passado: história oral. Trad. Lólio Lourenço de Oliveira. Rio de Janeiro, Paz e Terra, 1992.

SANTOS, Boaventura de Souza. Pela mão de Alice - o social e o político na pósmodernidade. São Paulo: Cortez, 1995.

1 pereira.milena@gmail.com - Graduação em Pedagogia pela Faculdade de Formação de Professores da Universidade do Estado do Rio de Janeiro, é graduanda em Estudos de Mídia na Universidade Federal Fluminense. Participou, pela Universidade do Estado do Rio de Janeiro, do Núcleo de Pesquisa e Extensão Vozes da Educação: História e Memória das Escolas de São Gonçalo; do Grupo de Pesquisa Formação em diálogo: narrativas de professoras, currículos e culturas; e do Grupo Linguagens, leituras e tecnologias na escola. Pela Universidade Federal Fluminense, participou do GRECOS (Grupo de Estudos sobre Comunicação e Sociedade), e do coLAB (Meta Laboratório de Comunicação, Tecnologias da Memória e Redes Colaborativas). Atualmente é bolsista de iniciação científica no projeto "O estatuto da colaboração: Apropriações da Web para processos de construção coletiva de narrativas".

2 nhpcdasilva@hotmail.com - Licenciada em Pedagogia pela Faculdade de Formação de Professores da Universidade do Estado do Rio de Janeiro.

3 jacquelinemorais@hotmail.com - Graduação em Pedagogia pela Universidade do Estado do Rio de Janeiro (1990), Mestrado em Educação pela Universidade Federal Fluminense (1998) e Doutorado em Educação pela Universidade Estadual de Campinas (2006). Atualmente é profes- sora adjunta da Universidade do Estado do Rio de Janeiro, atuando na Faculdade de Formação de Professores e no Instituto de Aplicação Fernando Rodrigues da Silveira - CAp-UERJ. É líder do Grupo de Pesquisa "Formação em diálogo: narrativas de professoras, currículos e culturas". É pesquisadora do "Núcleo de Pesquisa e Extensão Vozes da Educação História e Memória das Escolas de São Gonçalo". Pesquisa e publica principalmente sobre os seguintes temas: formação inicial e continuada de professores, aprendizagem da leitura e escrita, alfabetização e cotidiano escolar. É Procientista da UERJ. 